\title{
Pharmacological Chaperone Therapy for Gaucher Disease - A Patent Review
}

\author{
Abstract \\ Introduction. Mutations in the gene encoding for acid $\beta$-glucosidase $(\beta$ - \\ glucocerebrosidase, GlcCerase) are in the origin of Gaucher disease (GD), the \\ lysosomal storage disorder with the highest prevalence. Such mutations in GlcCerase \\ give rise to significant protein misfolding effects during translation in the endoplasmic \\ reticulum and reduction in enzyme trafficking to the lysosome, which result in \\ progressive accumulation of glucosylceramide (GlcCer). The main treatment for \\ Gaucher disease is enzyme replacement therapy (ERT), in which defective GlcCerase is \\ supplemented by active enzyme. The iminosugar glycosidase inhibitor $N$-(n-butyl)-1- \\ deoxynojirimycin (NB-DNJ; miglustat, Zavesca ${ }^{\mathrm{TM}}$ ) is used in a second treatment \\ modality known as substrate reduction therapy (SRT). At the beginning of the $21^{\text {st }}$ \\ century a third therapeutic paradigm that advocates the use of active site-directed \\ competitive inhibitors of the enzyme to restore its activity in the lysosome, namely \\ pharmacological chaperone therapy (PCT), was launched. This counterintuitive strategy \\ relies in the capability of such inhibitors to promote the correct folding and stabilize \\ mutant forms of lysosomal enzymes, such as GlcCerase, as they pass through the \\ secretory pathway. \\ Areas covered. This review summarizes the different approaches to implement the \\ concept of pharmacological chaperone therapy for Gaucher disease by discussing the \\ relevant research, patents and patent applications filed in the last decade. \\ Expert opinion. Ten years after PCT was first suggested, the time has come to dissect \\ whether the expectations were well founded or not on the basis of the transfer of the \\ concept to the clinics. While the significance of PCT remains a matter of debate, the
}


great interest gathered in relatively few years reflects its broad potential scope, well beyond GD. In fact, the resolute involvement of the pharmaceutical industry cannot be explained on the basis of the limited economical revenue associated to GD therapies but on a long-term view that focuses on the potential of the PCT concept in many other protein-folding diseases. The fact that PCs can be designed to cross the blood-brain barrier makes them candidates for the treatment of neuronopathic forms of GD that are not responsive to ERT. Combined therapies offer even broader possibilities that deserve to be fully explored.

Keywords: Ambroxol; Chemical chaperones; Folding diseases; Gaucher disease; Glucocerebrosidase; Glycosidase inhibitors; Iminosugars; Isofagomine; Lysosomal storage disorders; Nojirimycin; Pharmacological chaperone therapy 


\section{Introduction}

The lysosomes are cellular organelles specialized in the enzymatic digestion and recycling of exogenous and endogenous cellular debris. Lysosomal catabolic pathways normally involve the regulated action of a series of enzymes; inappropriate performance of any of the multiple hydrolytic enzymes involved in these cascades may lead to abnormal storage of undegraded substrates. Excessive accumulation of some of these substances is at the origin of a variety of cellular dysfunctions that can potentially lead to a range of pathologies commonly known as lysosomal storage disorders (LSDs) [1-4]. LSDs are a clinically heterogeneous group of genetically inherited (most of them in an autosomal recessive pattern) disorders often (but not solely) caused by the deficiency in the activity of a particular lysosomal enzyme.

There are over 60 different LSDs characterized by the lack of sufficient enzymatic activity to prevent the accumulation of specific substrates. Each unique disorder is caused by deficiency or dysfunction of a different enzyme [1]. The most prevalent group is associated to the abnormal storage of glycosphingolipids, a complex family of structural components of mammalian cell membranes that are involved in fundamental processes such as cell adhesion and signal transduction modulation [5]. LSDs are classified according to the accumulated metabolite and named after the physicians that firstly reported their clinical manifestations (Table 1). Each individual LSD is rare, though altogether their estimated incidence is one in 5000 to 10000 live births in Western countries, which is only slightly less common that cystic fibrosis (CF), one of the most frequently occurring genetic diseases. However, the extremely diverse phenotypic and pathophysiologic profiles, from virtually asymptomatic to serious neurological affections, have consistently hampered diagnosis and investigation for decades. In fact though most of LSDs were identified in the $19^{\text {th }}$ century, lysosomal 
involvement was not established until the 1960's [6], just few years after lysosome organelles were discovered [7]. Among the different therapeutic approaches under investigation, parenteral infusion of exogenous enzymes to process accumulated substrate (enzyme replacement therapy, ERT) has been shown so far the most effective [8]. Although ERT has proven beneficial for the most prevalent LSDs, including the most prevalent types of Gaucher ( $\beta$-glucocerebrosidase deficiency) or Fabry ( $\alpha$ galactosidase A deficiency) diseases, many other LSD patients still remain untreated. A second treatment modality known as substrate reduction therapy (SRT) consists in the administration of an inhibitor of the biosynthesis of glucosylceramide through inactivation of a ceramide glucosyltransferase, glucosylceramide synthase, thereby limiting accumulation of GlcCer [9]. In the last decade, a new therapeutic approach focused on recovering the activity of the endogenous dysfunctional enzymes, namely the pharmacological chaperone therapy (PCT; the term chemical chaperone therapy is indistinctly used in the literature), has emerged as a promising alternative [10]. This review will dissect the contribution of PCT to the advance in enzymopathy treatment of Gaucher disease, the LSD with the highest prevalence and often considered as a model for other LSDs, emphasizing on those that were translated into protected applications and technologies.

\section{Protein folding in lysosomal storage disorders}

The origin of protein dysfunction causing LSDs is diverse; however, abnormal protein folding during biosynthesis in the endoplasmic reticulum (ER) is often observed. As in many other diseases caused by protein misfolding, such as cystic fibrosis or $\alpha 1$ antitrypsin deficiency, certain inherited genetic deficiencies are translated into aberrant peptide sequences with reduced folding capabilities [11]. Lysosomal enzymes are 
normally synthesized via the rough endoplasmic reticulum in each cell. They are then trafficked to the Golgi for maturation and finally targeted to the lysosome (Figure 1, Pathway A). Trafficking between the ER and the Golgi apparatus is however interrupted when, as a consequence of certain gene mutations, the expressed proteins do not fold properly. Since ensuring accuracy in cellular functions critically depends on correct protein folding, cells have evolved their own protein quality control systems, namely the ER-associated protein degradation (ERAD) pathway, that efficiently clear off proteins that do not fold correctly or within the expected time frame in the ER (Figure 1, Pathway B). Ironically, in spite of their conformational deficiencies, in many of the misfolded lysosomal enzymes the catalytic site is preserved and would still be active enough in the lysosome to prevent abnormal substrate accumulation but, as a consequence of the severity of the protein quality control system, they would never have the opportunity to exert its function.

A variety of characterized gene mutations, ranging from single base substitutions to whole gene deletions, are known to lead to deficient enzyme or enzyme activity associated to LSDs [12-16]. The severity of disease manifestation is somewhat linked to the residual activity of the mutant enzyme. In the most dramatic cases patients, infants, are often developmentally or mentally retarded and rarely survive the first year of life. In other cases, symptoms only appear during adulthood due to progression of substrate accumulation (Table 1). The therapeutic goal of the various approaches to treat lysosomal enzymopathies is to restore the balance between the influx and degradation of the accumulated substrates (Figure 2).

\section{The Gaucher disease}


Gaucher disease (GD), named after the French physician Phillipe Gaucher who described the symptoms in 1882 [17], is a lysosomal storage disorder associated to the dysfunction of $\beta$-glucocerebrosidase (acid $\beta$-glucosidase, GlcCerase; EC no.3.2.1.45) that results in the accumulation of glucosylceramide (GlcCer) [18]. Accumulation usually takes place preferentially in macrophages but also in organs such as the liver, spleen, kidney, lung and even the brain and bone marrow. GD, caused by a recessive mutation in a gene located on chromosome 1, is the most prevalent LSD and affects overall to one in each 20000 live births on the basis of epidemiologic studies performed in the developed countries (Table 1) [19]. Nevertheless, in certain populations the frequency is much higher: among the Ashkenazi Jews, one in 450 to 800 live births (depending on the data source) is affected by GD. Little data are available from the situation in under-developed countries, but growing consciousness of GD frequency in developing regions such as Asia and South America clearly points to a pan-ethnic incidence.

As a consequence of the variety of organs affected by glucosylceramide accumulation, disease manifestation may differ between different patients. Visceral (e. g. splenomegalia and hepatomegalia), blood (e. g. anemia and thrombocytopenia), bone, or neurological affections are the most common symptoms; however the precise mechanisms by which glucosylceramide storage originate them is still unclear. A broad series of other less typical presentations have also been reported [20]. While visceromegalia is generalized in all cases, the incidence of the other phenotypes is, to some extent, related to the variant of the disease (Table 2).

There are three clinical GD disease variants, depending on the severity of the neurological involvement. Type 1 GD, also known as the non-neuronophatic or adult variant (Mendelian Inheritance in Man number MIM\#230800), is the most common and, 
as a consequence, the best characterized of all LSDs. However, symptomatology, severity and progression are heterogeneous in type 1 GD patients. In fact disease manifestation varies from childhood to adultness, indistinctly. Type 2 (MIM\#230900) and type 3 (MIM\#231000) variants involve neuronopathic affections. In type 2 GD there is a rapid progression of the disease that severely affects the central nervous system (CNS) in newborns and very rarely patients survive the second year of life. In type 3 GD progression is slower and disease shows up from childhood or adolescence (Table 2).

Diagnosis of Gaucher disease has usually been performed by measuring $\beta$ glucocerebrosidase activity in cultured cells (e. g. peripheral blood leucocytes or skin fibroblasts) [21], but DNA-profiling techniques are taking over. DNA testing has improved diagnostic accuracy not only for patients but also for carrier individuals and, in addition, may facilitate building up intimate genotype/phenotype correlations [22-24]. Over 300 mutations have been so far characterized [25], though two of them (c.1226A $>$ G leading to N370S and c.1448T $>$ C leading to L444P) were found in more than $60 \%$ of the cases (Table 3). According to calculations based on the X-ray structure of the native enzyme, most of the mutations would induce only minor conformational and activity drops [26]. Despite this knowledge, the ability to make prognostic predictions from genotypic data is rather limited. The N370S allele is by far the most common mutation, affecting to ca. $1 \%$ of US population (6\% of Askenazy Jews) [27]. In Western countries, an association can be drawn between the presence of the N370S allele in combination with other mutation and type 1 GD. Conversely, the L444P allele is most frequently associated to the neuronopathic variants. In spite of the limited knowledge of certain key molecular aspects, due to the heterogeneity of manifestations in a relatively small clinical population, Gaucher 
disease is considered a suitable model for other less common but equally devastating LSDs. In fact it has been tacitly accepted that therapeutic innovations towards the different variants of GD, apart from the obvious benefit for GD patients, may anticipate a brighter future for those affected by other LSDs.

As above outlined, the obvious therapeutic goal towards GD is to achieve equilibrium between the biosynthetic and degradation pathways within the cell in order to maintain homeostasis. Therefore, the enzymes responsible for the biosynthesis and degradation of glucosylceramide (glucosylceramide synthase and $\beta$-glucocerebrosidase, respectively) have emerged as the most important therapeutic targets in GD [28]. Different strategies to inhibit the former or activate, rescue or supplant the latter have been investigated in the last decades [3].

\section{Therapeutic milestones and pitfalls in Gaucher disease}

As a consequence of the relatively small number of individuals affected by and their heterogeneity, Gaucher disease has certainly never been attractive for the pharmaceutical industry, which is also true for other LSDs. Initial therapeutic approaches were restricted to symptom management, including pain relief, blood transfusions, orthopedic surgery, and organ removal. For ages, the sole pipeline to feedback alternative therapeutic development resulted from the knowledge in lysosomal functioning gained from academic research. Within orphan drug legal frame, however, the 80 's have witnessed the transference of this knowledge into therapeutically useful LSD treatments. This fact, together with the rising market associated to LSD management (estimated in US\$ 2.8 billions), has woken the interest of pharmaceutical companies. The therapeutic approaches developed over the years are chronologically collected in Figure 3. 
The first successful treatment for GD, enzyme replacement therapy (ERT), was introduced in the clinics at the beginning of the 90's. The therapy consists on the infusion of an exogenous recombinant enzyme to take over the mission that the endogenous mutant one is unable to perform (Figure 4C) $[3,8]$. Many of the visceral and skeletal manifestations of GD vanish upon regular treatment with a recombinant $\beta$ glucocerebrosidase. The fact that patients may recover their quality of life within 2-3 years has given ERT a privileged therapeutic status. Genzyme has remained as the sole supplier for this type of therapeutics for GD ever since (imiglucerase or Cerezyme ${ }^{\circledR}$ ) but very recently a new enzyme preparation (Velaglucerase $\alpha$, VPRI®, Shire Human Genetic Ther, USA) has been approved by FDA [29], and a second one (Taliglucerase $\alpha$, Uplyso ${ }^{\circledR}$, Protalix BioTherapeutics, Israel) is expected to get approval shortly [30]. Furthermore, ERT in Gaucher disease has been considered a paradigm that inspired similarly successful approaches. Several promising candidates towards other LSDs are presently either approved by FDA (e. g. Fabrazyme ${ }^{\mathrm{TM}}$ from Genzyme, in Fabry disease) or in advanced clinical trials [1,31,32].

Unfortunately, the scarce permeability of the blood-brain barrier to macromolecules limits ERT efficiency to non-neurologically affected GD individuals (type I). Type 2 and type 3 GD patients cannot benefit from this therapy. In addition, the cost of a single treatment (100-200 k\$ per patient per year) that would require lifelong commitment makes judicious use of the therapy mandatory. A conceptually complementary approach to ERT is the reduction in the influx of the accumulated substrate. Provided a residual $\beta$-glucocerebrosidase activity is remaining (which is the case in most GD patients), inhibition of the substrate producing enzyme may facilitate clearance (Figure 4D) $[9,33]$. The concept of substrate reduction therapy (SRT) was first demonstrated in GD by Shukla and coworkers by using a small 
molecule inhibitor of glucosylceramide synthase [34]. The use of small molecule inhibitors (e. g. iminosugars) for the treatment of GD instead of recombinant enzymes was very sound in order to develop more "drugable" candidates with better BBB permeability $[35,36]$. Unfortunately, SRT has not succeeded so far in bringing up suitable candidates for treatment of neuronophatic variants [37] and still the benefits of the treatment in type 1 GD do only recommend this therapy in patients naïve to ERT [38]. The most representative of this type of compounds, $N$-butyl deoxynojirimycin (NB-DNJ, Miglustat ${ }^{\mathrm{TM}}$, Actelion Pharma, Switzerland) was approved by the FDA and EMEA in 2003 for use in adults with type 1 GD who have medical contraindications to enzyme replacement therapy. Similar drug-based therapies are also being investigated in advanced clinical trials for Fabry, Tay-Sachs, Sandhoff, Niemann-Pick diseases or $\mathrm{G}_{\mathrm{M} 1}$ gangliosidosis [39].

So far, ERT and SRT are approved medical treatments for GD that have significantly contributed to improve the life quality of type 1 patients. However, they still are inefficient to target the central nervous system (CNS). Managing neurological affections represents nowadays the major challenge. Gene therapy (GT) [40,41] and stem cell therapy (SCT) $[42,43]$ or bone marrow transplantation (BMT) $[12,44]$, long-term promises towards this end, have slowed down their progress due to the problems associated to mutagenesis and malignant-cell transformation [45-47] or donor limitations and procedure-associated risks.

\section{Pharmacological chaperone therapy.}

As already discussed, most LSDs stem from the insufficient enzymatic activity in the lysosome as a consequence of the poor trafficking of a misfolded enzyme. A decade ago a pioneering report by Fan and co-workers demonstrated that in certain cases small 
molecule ligands of a mutant glycosidase enzyme (e. g. substrate-like competitive inhibitors) might promote those conformational changes that are required for efficient folding [48]. Though subtle, this chaperoning activity seems to be instrumental in order to rescue the enzyme from ERAD and deliver it through the appropriate pathways to its final destination in the lysosome $[1,49]$. It is assumed that at the massive lysosomal substrate concentration, the inhibitor would be replaced from the active site of the enzyme and the metabolic activity recovered (Figure 4E). This counterintuitive concept (namely, using inhibitors to elicit enzyme activity) set the basis for a brand new therapeutic approach to LSDs: the pharmaceutical chaperone therapy (PCT). Proof of principle of the feasibility of this therapeutic approach has been given for some of the most relevant LSDs, including $\mathrm{G}_{\mathrm{M} 1}$ gangliosidosis [50], Fabry disease (FD) [51], Pompe disease (PD) [52] and, of course, GD [53].

Conceptually, rescuing mutated proteins using sub-inhibitory concentrations of pharmacological chaperones (PCs) is advantageous as compared to the established therapies (ERT and SRT). PCT aims to achieve a therapeutic effect without the administration of potentially immunogenic exogenous proteins (ERT) or disregulating the glycosphingolipid metabolic pathways (SRT). Rather than focusing in reducing the influx of substrate (SRT), PCT tackles the cause of the accumulation by mending the functionality of the endogenous enzyme. In addition, the use of PCs has the potential to overcome the limitations of ERT concerning biodistribution (in particular concerning BBB permeability), administration (requiring lifelong regular infusions) and eventually costs. It has been demonstrated that some pharmacological chaperone candidates cross over the BBB, therefore being potentially useful for the treatment of patients with neuronophatic affections. For instance, NB-DNJ, used in SRT modality for GD and a potential chaperone for the acid $\alpha$-glucosidase involved in Pompe disease, evenly 
distribute in a variety of tissues in model animals [54] and NOEV ( $N$-octyl-4-epi- $\beta$ valienamine), a chaperone for the $\beta$-galactosidase involved in $\mathrm{G}_{\mathrm{M} 1}$ glangliosidosis, is rapidly localized in most areas of the brain [50] (Table 4).

There are also some inherent limitations for PCT. The mutant enzyme should be (at least residually) active in the lysosome since the chaperoning activity in the ER would only improve protein folding, ERAD evasion and trafficking to the lysosome. If mutations affect the catalytic pocket, PCT is very likely to fail [55]. In addition, this chaperoning activity at the ER should be achieved at sub-inhibitory concentrations under lysosomal conditions and, therefore, a balance between folding enhancement and enzyme inhibition should be reached for each particular case.

In spite of these drawbacks, PCT has attracted a great interest in a relatively short timeframe stimulating a particularly fruitful synergy between academia and industry that has spread among several LSDs as well as other genetic protein folding disorders such as cystic fibrosis [56]. For instance, Miglustat ${ }^{\mathrm{TM}}$, already approved by FDA for the SRT modality of type $1 \mathrm{GD}$, is currently in phase II clinical trials for the treatment of cystic fibrosis [57]. At glance, the field is maturing fast in particular for the case of GD [53]. Many of the mutations associated to GD are located in the catalytic domain (e. g. N370S), however they rarely affect the catalytic pocket and, therefore, the metabolic activity is preserved to certain extent [58]. In such scenario, where the folding hurdle is associated to the enzyme active site, the investigation of substrate-like competitive enzyme inhibitors as pharmacological chaperones is particularly sound. This effort is translated into a growing arsenal of newly designed pharmacophores and applications. The substantial patenting activity in the field reflects the high expectations created around PCT. The most promising patent contributions concerning pharmacological 
chaperon therapy in Gaucher disease are collected in Table 5 and summarized in the following sections.

\section{Design of new pharmacological chaperones towards Gaucher disease}

Even though inducing the appropriate folding in a mutant protein can be achieved with chaperones that interact with any region on the protein, the search for molecular structures that could function as pharmacological chaperones has been largely dominated by the use of active-site specific ligands. The fact that such type of ligands (e. g. competitive enzyme inhibitors) can be rationally designed on the basis of enzyme structure knowledge is a main reason for this channel. Another one is the fact that many of the mutations associated to GD are actually located in the catalytic domain. Consequently, a significant amount of effort has been directed to bring up new pharmacophores that can fit in the GlcCerase active site and clamp the correct folding. Three basic premises are considered necessary to successfully achieve this task, namely high enzyme affinity and selectivity at the ER in order to induce the proper folding, suitable permeability and biodistribution and smooth dissociation from the enzyme at the lysosome. Most of the protocols seeking for potential pharmacological chaperones towards LSDs in general and GD in particular are based on the sequential consisting on (i) the identification of compounds that selectively inhibit the target enzyme from more or less diverse chemical libraries (in vitro), (ii) investigation of the mutant enzyme activity enhancement capability of the most interesting candidates in cell-based assays (ex vivo), and (iii) pathophysiologic evaluation in animal models (in vivo) [59].

\section{Glucocerebrosidase substrate-like pharmacological chaperones towards}

\section{Gaucher disease}


Iminosugars, the most prominent family of naturally occurring glycosidase inhibitors, hold a privileged status in the search for efficient chaperone candidates for PCT. Iminosugars resemble the structure of natural glycosides, except for the presence of a nitrogen atom in place of the endocyclic oxygen of the substrate $[60,61]$. They generally feature high affinity for the active site of glycosidases according to their hydroxylation pattern, eventually higher than the natural substrates, therefore acting as glycosidase inhibitors. In most cases, the therapeutic potential of the glycosidase inhibition capability of naturally occurring iminosugars is limited due to their rather poor selectivity within enzymes acting on anomeric glycosides (e.g., simultaneous inihibition of $\alpha$ - and $\beta$-glucosidases) as well as within isoenzyme series (e.g., simultaneous inhibition of neutral and acid $\alpha$-glucosidases). Nevertheless, in certain cases a useful chaperoning activity has been encountered in addition to their glycosidase inhibition capability. As a matter of fact, iminosugars were the first type of compounds systematically investigated as pharmacological chaperones and still are the main source of investigational drugs for GD and many other LSDs [62].

In one of the first examples of the above working procedure, Kelly and coworkers investigated the chaperoning abilities of a structurally diverse collection of compounds towards human GlcCerase, including natural and alkylated iminosugars [63]. This study lead to the discovery that sub-inhibitory amounts of $N$-nonyldeoxynojirimycin (NNDNJ, Chart 1) could be used to restore the $\beta$-glucocerebrosidase deficiency in cultured fibroblasts expressing the type 1 GD mutation N370S [64, 201]. The structural resemblance of this newly identified $\beta$-glucoserebrosidase chaperone with NB-DNJ (approved for SRT in type 1 GD in 2003) has called the attention on the reinvestigation of the precise role of the latter in glucosylceramide management. Thus, Pocovi and coworkers have demonstrated that, in addition to the well documented substrate- 
deprivation effect, NB-DNJ leads to significant activity increases for several mutant $\beta$ glucoserebrosidases (e. g. 2-fold increase in the N370S mutant) expressed in COS-7 (immortalized African green monkey kidney fibroblast) cells [65].

Besides NN-DNJ, other alkylated iminosugars were identified from this library as potential pharmacological chaperones for mutant $\beta$-glucocerebrosidases associated to GD. For instance, $N$-octyl-2,5-anhydro-2,5-imino-D-glucitol has been shown to preferentially enhance the activity of the G202R mutant [64]. Up to 7-fold increases in enzyme activity were observed with isofagomine derivatives alkylated with sterically bulky adamantane substituents (Chart 1), though the chaperone concentration required to achieve this activity enhancement $(>100 \mu \mathrm{M})$ is probably unpractical from the therapeutic point of view [66]. However, none of these chaperones were effective for the L444P mutant enzyme, associated to neuronopathic GD variants.

In a different invention, Fan and coworkers reported that minute amounts of $N$-dodecyl DNJ could elicit $\beta$-glucocerebrosidase activity (95\% activity increase at $0.5 \mu \mathrm{M})$ in cultured N370S fibroblasts. Naturally occurring calystegine $\mathrm{B}_{2}($ Chart 1$)$ and other memers of the calystegine iminosugar family were claimed to exhibit a very significant chaperone activity in fibroblasts from a Gaucher patient with the L444P/L444P genotype (230\% activity increase at $10 \mu \mathrm{M}$ for calystegine $\left.\mathrm{B}_{2}\right)$ [202-204]. This is remarkable considering that the L444P mutation is not located at the catalytic domain of GlcCerase and has been shown to be generally refractive to active-site directed chemical chaperones. Unfortunately, these results have not been the object of further publication and remain to be confirmed. Additionally, these inventions showed the first evidences of the chaperoning properties of isofagomine [67] and isofagomine derivatives towards $\beta$-glucocerebrosidase. 
Isofagomine (IFG, Chart 1) is probably so far the most representative investigational pharmacological chaperone for GD. IFG strongly binds to wild-type and mutant $\beta$ glucocerebrosidases ( $\mathrm{IC}_{50} 60 \mathrm{nM}$ ), helping misfolded mutants to fold correctly. In vitro studies have shown that IFG enhances 2-to-3 fold the activity of N370S mutant $\beta$ glucocerebrosidase. IFG enhances mutant enzyme activity by assisting folding in ER and lowering the optimal enzyme working $\mathrm{pH}$ (from 6.4 to 5.2, closer to that found in the lysosome) [68]. Additionally, it has been shown that IFG plays a role in the enzyme trafficking enhancement [67]. Interestingly, these effects are achieved at relatively low concentrations, therefore limiting the adverse effects associated to the non-specific inhibition of other lysosomal or intestinal glycosidases [69].

Under the enthusiastic sponsorship of Amicus Therapeutics, synthetic approaches towards IFG (AT-2101, Plicera $\left.{ }^{\circledR}\right)[205,206]$ and formulations $[207,208]$ have arisen. Recent results have shown that IFG can reduce glucosylceramide levels even in L444P Gaucher fibroblasts. Importantly, this reduction was seen only following three-day incubation in IFG-free media, underscoring the importance of IFG removal to restore lysosomal GCase activity. Investigations in knock-in mouse models expressing L444P mutated $\beta$-glucocerebrosidase have evidenced dose-dependent enzyme activity increase ( 2 to 5 fold) in the brain [70,209]. Preliminary reports indicated that these effects were achieved within few weeks and are persistent after treatment withdrawn. In addition, a recently reported procedure for the monitoring of typical GD surrogate markers [210] indicated the progressive healthy cell functioning recovery upon IFG treatment. Using this GD surrogate markers monitorization procedure, formulations and tolerable dose regimes have been implemented for humans [211]. IFG has completed a phase II study [71] in patients receiving ERT and several others are in course to assess ex vivo response to the drug [72], its long term effects [73] and 
its safety, tolerability and efficacy in treatment-naive adult type 1 GD patients [74]. Unfortunately, the preliminary results of the latter study revealed scarce improvement in key GD markers and manufacturers do not expect IFG to enter Phase III development [75]. The high hydrophilicity of IFG is probably in part responsible for its poor performance in humans.

In order to avoid this drawback, less hydrophilic IFG derivatives are being alternatively investigated. C-Alkylated derivatives such as 6-nonyl IFG [212,213] (Chart 2) has been shown to increase $\beta$-glucocerebrosidase activity. While enzyme activation is not significantly higher than that reported with IFG, the concentration required to achieve it is several orders of magnitude smaller: whereas IFG achieves optimal enzyme activity at $30 \mu \mathrm{M}$, 6-nonyl IFG did at $3 \mathrm{nM}$ in cultured N370S human fibroblasts.

The presence of aliphatic chains in iminosugars may results in loose of selectivity as compared to the parent structures, due to non- specific interactions with hydrophobic pockets in the surroundings of the glycosidase binding site. As an alternative mode to reduce the hydrophilicity of IFG without affecting enzyme selectivity, Boyd and Lee disclosed halogenated IFG derivatives (F-IFG and Cl-IFG, Chart 2) [214,215]. Similarly to IFG, F-IFG and Cl-IFG are strong competitive glucocerebrosidase inhibitors in vitro (inhibition constant, $K_{\mathrm{i}}$, in the low nM range). However, in contrast with the former, the efficiency does not significantly decrease in cell-based assays, pointing to more favorable membrane-crossing capabilities for halo-IFGs. In vivo assays in mice further indicated interesting blood-brain barrier permeability. Halo-IFG extensively localized in the brain and induce a 2-to-3 fold increase in glucocerebrosidase activity at $10 \mathrm{mg} \cdot \mathrm{Kg}^{-1}$ (less than $10 \%$ of IFG dose required to elicit the same response).

Besides the thorough research around IFG and IFG derivatives sponsored by Amicus Therapeutics, many other iminosugar-based designs are under investigation. Most of 
them aim at improving the selectivity towards the target enzyme, a typical problem when using classical iminosugars. For instance, in addition to the chaperoning effect on the N370S mutant $\beta$-glucocerebrosidase, $\mathrm{NN}-\mathrm{DNJ}$ also produces a potentially dangerous inhibition of the lysosomal $\alpha$-glucosidase. In other to prevent this drawback, Asano and coworkers investigated alternative alkylation patterns that led to the identification of $\alpha-1-\mathrm{C}-$ octyl-DNJ (CO-DNJ, Chart 3) [76]. Later they found that $\alpha-1-$ C-nonyl-iminoxylitol (CN-DIX, Chart 3) was a much more selective inhibitor of GlcCerase [77,216]. Although the chaperoning capability of these iminosugar pseudo C-glycosides is smaller than that reported for NN-DNJ (1.7 to 2.0 fold and 1.2 fold activity enhancement in N370S and L444P Gaucher fibroblasts, respectively), they are remarkably selective and therefore do not interfere with the activity of other lysosomal or intestinal glycosidases.

In a different invention, Fan and coworkers reported a series of alkylated glucoimidazoles (alkyl-GIZ, Chart 3) as new potential $\beta$-glucocerebrosidase chaperones . The $\beta$-glucocerebrosidase inhibiting potency of these derivatives is remarkably high $\left(\mathrm{IC}_{50}\right.$ in the $\mathrm{pM}$ range in certain cases), however the selectivity issue was not addressed and the enzyme activity in cultured N370S patient cells only increased 2-fold upon incubation with GIZ $(300 \mu \mathrm{M})$ [217,218].

Glycosidase selectivity and membrane permeability are critical parameters that must be taken into consideration in the design of new pharmacological chaperones. Committed with these principles, a recently reported invention exploits the concept of " $\mathrm{sp}^{2}$ iminosugars" [78] for this purpose. It has been demonstrated that bicyclic iminosugars that incorporate a bridgehead nitrogen atom with substantial $\mathrm{sp}^{2}$ character (instead of the $\mathrm{sp}^{3}$ hybridization typical of classical iminosugars) behave as competitive inhibitors of glycosidases with tunable selectivity [79-84]. Bicyclic $\mathrm{sp}^{2}$-iminosugar analogues of the 
natural reducing alkaloid nojirimycin $(\mathrm{NJ}$; note that these compounds can be formally considered as reducing indolizidine-type glycomimetics) bearing lipophilic substituents, such as 5-N,6-O-(N'-octyliminomethylidene)nojirimycin (NOI-NJ) or its 6-thio derivative (6S-NOI-NJ) (Chart 3), are anomeric-specific inhibitors of $\beta$-glucosidases, including the lysosomal acid $\beta$-glucosidase associated with Gaucher disease [219]. The inhibitory activity was preserved for a range of glucocerebrosidase mutants including F213I, N370S and L444P. Furthermore, the inhibition potency was systematically stronger at neutral $(7.0, \mathrm{ER})$ than at acidic $(5.2$, lysosomal $) \mathrm{pH}$, which is expected to be favorable in order to promote chaperoning at the ER and further enzyme trafficking without compromising hydrolytic activity once at the lysosome. Mutation profiling of the chaperone effect of $\mathrm{sp}^{2}$ iminosugars evidenced relatively modest activity enhancements for the N370S mutation as compared with NN-DNJ. However in situ cell-based assays using patient fibroblasts revealed much higher activity increases (ca. 2.5 fold) for mutant enzymes associated to neuronopathic GD affections (F213I or G202R) [85]. An additional advantage of $\mathrm{sp}^{2}$ iminosugars in comparison with other pharmacological chaperone cores is that the synthetic scheme is very well-suited for molecular diversity-oriented strategies and therefore it might be possible to discover new candidates with improved chaperoning capabilities and high selectivity by finely tuning the molecular structure.

In addition to iminosugar-based scaffolds, other glycomimetic structures, e.g. aminocyclitols, have shown interesting chaperoning capabilities. In a pioneering report, Ohno and Suzuki demonstrated that $N$-octyl- $\beta$-valienamine (NOV, Chart 4), a $\beta$ selective glucosidase inhibitor [86], up-regulates certain mutant $\beta$-glucocerebrosidases in cultured fibroblasts $[87,88]$. The best results (6-fold activity enhancement) were obtained for the F213I mutation. Interestingly, the epimeric analog resembling the 
galactose configuration ( $N$-octyl- $\beta$-3-epi-valienamine NOEV) has also been shown to chaperone mutant acid $\beta$-galactosidases involved in $\mathrm{G}_{\mathrm{M} 1}$ gangliosidosis [89]. More recently, Delgado and coworkers have identified a series of selective $\beta$ glucosidase inhibitors from a library of $N$-alkyl aminoinositols. Although their chaperoning activity is relatively modest [58], some of these compounds are able to stabilize imiglucerase, the recombinant enzyme used for ERT, when subjected to thermal denaturation conditions [220]. Imiglucerase stabilization is somehow dependent on the length of the alkyl chain, the best results being obtained with the longest (hexadecyl) aliphatic chain [90] (Chart 4).

\section{High-throughput library screening towards pharmacological chaperones for}

\section{Gaucher disease}

The cumulative data commented in the previous sections stress the necessity of a thorough mutation-based profiling of chemical chaperones to evaluate their therapeutic potential. Ideally, the information collected from screening should allow designing tailor-made chaperones for different mutant enzymes. Rational design of pharmacological chaperones still faces some important limitations, however, including the rather scarce number of molecular scaffolds at hand and the limited knowledge of the $3 \mathrm{D}$ structure of the target mutant enzymes. Most of the newly developed candidates are compounds with a glycomimetic topology stemming from enzyme inhibition studies that never have been tested in humans before and, therefore, they have first to be approved by the legal authorities.

In a desperate attempt to take a shortcut in the way to identify new potential pharmacological chaperones, several generic libraries have been assayed for thermal enzyme denaturation inhibition capability using high-throughput screening (HTS) 
techniques. The potential of this approach to lead to positive heats as potential chemical chaperones is paradigmatically illustrated with the case of Ambroxol (ABX, Chart 5). $\mathrm{ABX}$ is a mucolytic drug approved for its use in newborns that was identified among other 1039 FDA-approved small molecules as a very efficient stabilizer of the recombinant enzyme imiglucerase in thermal denaturation conditions [221]. ABXmediated thermal stabilization has been demonstrated for wild-type and mutant $\beta$ glucocerebrosidases. The interaction between $\mathrm{ABX}$ and $\beta$-glucocerebrosidase results in a very interesting inhibition pattern: it switches from highly efficient at neutral (ER) $\mathrm{pH}$ to virtually undetectable in acidic (lysosome) conditions. These features are probably responsible for observed enhancement in mutant (N370S and F213I) glucocerebrosidase activity, up to 6-fold as determined in human fibroblasts [91,221].

The discovery of $\mathrm{ABX}$ represents a milestone in the search for therapeutic treatments for GD that will surely influence further research on other LSDs. So far, most of the strategies were focused on screening candidates selected on the basis of their glycosidase inhibition capabilities, assuming that active-site specific ligands are the best potential candidates to help enzyme trafficking and restore enzyme activity. However, HTS has opened the door to evaluate a much wider diversity of structures not exclusively targeted to the enzyme active site. Ironically, while in principle ABX could potentially interact with the $\beta$-glucocerebrosidase at any position, hydrogen/deuterium exchange mass-spectrometry and molecular modeling experiments indicate that binding takes place at the catalytic domain [91]. On the other hand, the initial screening principle, focused on glycosidase stabilization rather than on inhibition, may also be considered better suited for the final therapeutic goal.

The case of ABX is not anecdotic. Screening of the same library versus the $\beta$ hexosaminidase involved in $\mathrm{G}_{\mathrm{M} 2}$ glangliosidosis let the same authors to identify 
pyrimethamine as a potential chemical chaperone for this enzyme [92,222]. Regrettably, phase I clinical trials [93] were recently suspended due to insufficient funding. From a thorough preliminary screening of the Maybridge library (ca. 50000 compounds, see www.maybridge.com) a number of non-carbohydrate small molecules were identified as selective $\beta$-glucocerebrosidase inhibitors. A focused screening of the most active compounds showed that certain structures featured chaperoning activity towards N370S mutant $\beta$-glucocerebrosidase, though not necessarily correlated to their inhibitory potency. The most interesting structures, 5-(3,5-dichlorophenoxy)- $N$-(4pyridinyl)-2-furamide (HTS02324) and 5-(4-tolylthio)quinazoline-2,4-diamine (MWP01127) (Chart 5), are mixed-type glucocerebrosidase inhibitors with optimal performance at neutral $\mathrm{pH}$ and poor binding at acidic $\mathrm{pH}$. This feature, together with their membrane permeability, is probably the reason for their efficient performance: 1.5 2.5-fold enzyme activity enhancements were measured in GD fibroblasts (homozygote N370S and F213I mutations) using as little as $10 \mu \mathrm{M}$ of HTS02324 and MWP01127. This performance is not far from that obtained with IFG, a much stronger glucocerebrosidase inhibitor ( IC $_{50}$ values $0.06,5$ and $8 \mu \mathrm{M}$ for IFG, HTS02324 and MWP01127, respectively) [223,224].

\section{Computational discovery of pharmacological chaperones for Gaucher disease}

In addition to the above commented methods for identifying new pharmacological chaperones to promote the appropriate folding of mutant $\beta$-glucocerebrosidases, Futerman and co-workers disclosed a computational platform to design optimal GDtargeted drugs [225]. Their invention consists on a method to generate sets of 3Dcoordinates of mutant $\beta$-glucocerebrosidases on the basis of the available crystallographic data, from which the structure of compounds capable of correcting the 
impaired enzyme activity could be computationally optimized. While the proof of concept was not completed in the invention report, the potential of computationally assisted pharmacological chaperone design is expected to improve as more structural data on GlcCerase:chaperone complexes become available.

\section{Expert Opinion}

The body of results commented and the relatively short time span in which they were generated stresses the prospects of PCT towards GD. The enthusiastic support of the pharmaceutical industry (it is important to highlight that the knowledge developed in the field does not arises exclusively from the academic field) cannot be understood as a mere commercial interest on GD treatment because the potential market, though eager for receiving improved treatments, is very limited. This attitude may reflect the potential of PCT as a general approach to the growing diversity of diseases associated to inappropriate protein folding, which is not limited to LSDs but includes also several pathologies that represent major health problems in developed countries. Thus, some recent results have established a link between GD and Parkinson disease [94-96]. It is worth mentioning that the first proof-of-concept of PCT did not concern a LSDassociated enzyme, but mutant forms of theV2 vasopressin receptor (V2R), which by failing to traffic to the cell membrane causes nephrogenic diabetes insipidus [97]. Any molecule capable of promoting structural adaptation is a potential pharmacological chaperone, including inhibitors (if reversibly bound), as shown for various V2R mutants in this pioneer study and further on in several LSDs. The key aspect is specificity: pharmacological chaperones exert a specific action on a given target molecule [10]. It should be emphasized that repair by pharmacological chaperones implies an almost "mutation-specific" mode of action, inasmuch as their binding is determined by a 
particular conformation possibly not common to all mutant forms of a given receptor. Investigations on the use of pharmacological chaperones to correct protein conformational defects associated with a variety of human diseases, including prion disease, Alzheimer disease, retinitis pigmentosa, cancer, cystic fibrosis or nephrogenic diabetis insipidus has been the subject of several excellent reviews [11,98-101]. Probably, the limitations of the other GD therapeutic approaches investigated so far (mainly ERT) have also contributed to the increase interest in PCT. This interest is maintained even considering the conceptual limitations of PCT: (i) it is restricted to cases in which the mutant enzyme folding is chaperone-responsive, (ii) preserves certain residual activity itself, and (iii) a thorough mutation-based profiling of chemical chaperones is required to attain the expected therapeutic relevance.

The fact that the most common mutant glucocerebrosidases are chaperone-responsive converted GD into a paradigmatic disease to assess the scope of PCT. Although much knowledge has being gained during the last decade, still major goals remain unmet. The limitations of IFG, the deepest investigated chemical chaperone for GD so far, might serve to illustrate them. IFG is an excellent glucocerebrosidase inhibitor but only modestly selective. IFG is such a strong inhibitor that glucocerebrosidase activity enhancement only takes place after it is washed out of the lysosome. In addition, IFG hydrophilicity limits its intracellular distribution and therefore the dose required to elicit the desired effect turns much higher than theoretically needed. Probably the skills to rationally design chaperones that specifically target the mutant enzyme in a $\mathrm{pH}-$ switchable manner are the most demanded. Modulating the basicity of the chaperone, e.g. by replacing the amine-type nitrogen of iminosugars or azasugars into pseudoamide functional groups, might offer an interesting tool, but many mechanistic questions remain to be answered $[85,102]$. 
An ideal chaperone should have weak or no inhibitory effects and high enzyme activity enhancing capability [103]. Future development of chemical chaperones should take full advantage of the HTS and computational methodologies that are being added to the toolbox to commit with this criterion. Leaps forward in this direction were reported recently. Inventions registered by Summit Corporation described a method for the identification of compounds from natural and synthetic iminosugar libraries that function as pharmacological chaperones but without inhibiting the chaperoned enzyme $[226,227]$. Further on, the same authors have shown that combination of the chaperoning properties towards mutant glucocerebrosidases (e. g. N370S) of "classical" (active-site enzyme ligands) chaperones such as IFG can be improved when coformulated with the non-active-site chaperones identified in their screenings [228]. The rapid development of the field is a consequence of the contribution of a growing number of research teams applying their own expertise. This intuitively positive feature is, probably, the reason why comparison of independently obtained results is delicate. The methods to determine, for instance, enzyme activity enhancement differ from one to another and are often based on protocols that require cell lysis, which might not accurately reflect enzyme activity at the lysosome. Future maturation of the field will hopefully bring more standardized protocols, preferentially allowing determinations to be made in situ in living cells. A possible solution to this issue has been recently delineated by Aerts and co-workers by developing fluorescent probes for the highly efficient and specific labeling of $\beta$-glucocerebrosidase molecules in intact cells in vitro and in vivo [104].

The shortage on the production of the recombinant $\beta$-glucocerebrosidase Cerezyme ${ }^{\circledR}$, the drug of reference for most type 1 GD patients, during the past year has dramatically illustrated the risks associated to single drug management of GD. The short supply 
arose because of the temporary shutdown of Genzyme's Allston (Massachusetts) plant due to a virus contamination in June 2009. The entry of new recombinant enzymes in the market for the treatment of GD (e.g. Velaglucerase $\alpha$ from Shire and, presumably, Taliglucerase $\alpha$ from Protalix-Pfizer) will surely reduce the menace as well of the costs of individual treatments. In any case, the use of recombinant enzyme biopharmaceuticals is intrinsically associated to low stability in biological media as well as impossibility to cross the blood brain barrier, making enzyme replacement therapy hopeless for neuronopathic type 2 and type 3 GD. The sub-optimal pharmacodynamics and pharmacokinetics of recombinant glucocerebrosidase has always been a concern and the development of formulations with better bioavailability, stability and efficiency, a battle horse. In this context PCT, based in small molecules that can be tailored to cross biological barriers, might complement rather than compete with ERT. It has been demonstrated that chemical chaperones can increase not only thermal stability of recombinant glucocerebrosidase but also half-life in biological media $[105,106]$, thus prompting re-evaluation of "combined therapies" even for type 1 GD. For some of the chemical chaperones under investigation, their potential application in combined therapy has been already claimed. Probably, the imiglucerase half life-enhancing effect of $\mathrm{ABX}$ (3-fold at $20 \mu \mathrm{M}$ ) is the best example so far reported [221]. But also iminosugars such as isofagomine [107], DNJ [108] or NB-DNJ [52,109] have been shown to exhibit beneficial effects. But the prospects of combined therapies are not only aimed at preparing stabilized formulations of recombinant enzymes. For instance, in line with earlier work of Kopito aimed at blocking ERAD [110], it has been recently proposed the use of pharmacological chaperones and proteasome inhibitors as a combined therapeutic approach to enhance lysosomal enzyme activity [111]. 
Coordinating the efforts of the companies developing biopharmaceuticals and chemical chaperones with those of chemists, biochemists, biologists and clinicians involved in academic research may open new venues for GD treatment that, at their turn, can delineate the way for other LSDs as well as other folding diseases.

\section{Acknowledgements}

The authors thank the the Spanish Ministerio de Ciencia e Innovación (contract numbers CTQ2007-61180/PPQ and SAF2010-15670), the Fundación Ramón Areces, the Junta de Andalucía (Project P08-FQM-03711) and the European Union for sustained financial support in the field covered by this review.

\section{References}

1. Barrange JA, Cabrera-Salazar MA. Lysosomal storage disorders. NY: Springer, 2007

2. Futerman AH, van Meer G. The cell biology of lysosomal storage disorders. Nat Rev Mol Cell Biol 2004;5:554-65

3. Parenti G. Treating lysosomal storage diseases with pharmacological chaperones: from concept to clinics. EMBO Mol Med 2009;1:268-79

\section{* Introduction to the concept and potential of pharmacologic chaperones}

4. Meikle PJ, Fietz MJ, Hopwood JJ. Diagnosis of lysosomal storage disorders: current techniques and future directions. Expert Rev Mol Diagn 2004;4:677-91

5. Wennekes T, van den Berg RJBHN, Boot RG, et al. GlycosphingolipidsNature, function, and pharmacological modulation. Angew Chem Int Ed 2009;48:8848-69 
6. Hers HG. $\alpha$-Glucosidase deficiency in generalized glycogen storage disease (Pompe's disease). Biochem J 1963;86:11-6

7. De Duve C, Pressman BC, Gianetto R, et al. Tissue fractionation studies. 6 . Intracellular distribution patterns of enzymes in rat-liver tissue. Biochem J. $1955 ; 60: 604-17$

8. Pastores GM. Enzyme therapy for the lysosomal storage disorders: principles, patents, practice and prospects. Expert Opin Ther Pat 2003;13:1157-72

9. Smid BE, Aerts JMFG, Boot RG, et al. Pharmacological small molecules for the treatment of lysosomal storage disorders. Expert Opin Invest Drug 2010;19:1367-79

10. Bernier V, Lagacé M, Bichet DG, Bouvier M. Pharmacological chaperones: potential treatment for conformational disease. Trends Endocrinol Metabol 2004;15:5

11. Coehn FE, Kelly JW. Therapeutic approaches to protein misfolding diseases. Nature 2003;426: 905-9

* An excellent insight on the common thermodynamic and kinetic issues involved in protein misfolding disorders.

12. Grabowski GA, Kolodny EH, Weinreb NJ, et al. Gaucher disease: Phenotypic and genetic variation, Chapter 146.1. In Scriver CR, Beaudet AL, Sly WS, Valle D, eds. The metabolic and molecular bases of inherited disease. NY: McGrawHill, 2006. http://genetics.accessmedicine.com (last accessed $11^{\text {th }}$ Feb 2011)

13. Kornfeld S. Structure and function of the mannose 6-phosphate/insulinlike growth factor II receptors. Ann Rev Biochem 1992;61:307-30

14. Krivit W. Stem cell bone marrow transplantation in patients with metabolic storage diseases. Adv Pediat 2002;49:359-78 
15. MacDermot KD, Holmes A, Miners AH. Natural history of Fabry disease in affected males and obligate carrier females. J Inher Metabol Dis 2001;24:s13s14; discussion 11-2

16. Pastores GM, Weinreb NJ, Aerts H, et al. Therapeutic goals in the treatment of Gaucher disease. Seminars Hematol 2004;41:s4-s14

17. Gaucher PCE. De l'epithelioma primitif de la rate, hypertrophie idiopathique de la rate sans leucemie [academic thesis]. Paris, France, 1882

18. Beutler E, Grabowski GA. Glucosylceramide lipidosis-Gaucher disease. In: Scriver CR, Beaudet AL, Sly WS, Valle D. The metabolic and molecular bases of inherited diseases. 8th edn. NY: McGraw-Hill, 2001:3635-68

19. Zeller JL, Burke AE, Glass RM. Gaucher disease. JAMA patient page 2007;298:1358

20. Sidransky E. Gaucher disease: complexity in a "simple" disorder. Mol Genet Metab 2004;83:6-15

21. Raghavan SS, Topol J, Kolodny EH. Leukocyte $\beta$-glucosidase in homozygotes and heterozygotes for Gaucher disease. Am J Hum Genet 1980;32:158-73

22. Grabowski, GA. Phenotype, diagnosis, and treatment of Gaucher's disease. Lancet, 2008;372;1263-71

23. Beutler E, Gelbart T, Scott CR. Hematologically important mutations: Gaucher disease. Blood Cells Mol Dis 2005;35:355-64

24. Hruska KS, LaMarca, ME, Sidransky E. Gaucher disease: molecular biology and genotype-phenotype correlations. In Futerman AH, Zimran A, eds. Gaucher disease. Boca Raton: Taylor \& Francis, 2006:13-48 
25. Hruska KS, LaMarca, ME, Scott CR, Sidransky E. Gaucher disease: mutation polymorphism spectrum in the glucorebrosidase gene (GBA). Hum Mutat $2008 ; 29: 567-83$

26. Dvir H, Harel M, McCarthy AA, et al. X-ray structure of human acid- $\beta$ glucosidase, the defective enzyme in Gaucher disease. EMBO Rep 2003;4:704-9

27. Zuckerman S, Lahad A, Shmueli A, et al. Carrier screening for Gaucher disease: lessons for low-penetrance, treatable diseases. JAMA 2007;298: 1281-90

28. Sobera LA, Sundaravinayagan D, Dulsat C, Rosa E. Therapeutic targets for Gaucher's disease. Drug of the future, 2009;34:1001-4

29. Zimran A, Altarescu G, Phillips M, et al. Phase 1/2 and extension study of velaglucerase alfa replacement therapy in adults with type 1 Gaucher disease: 48-month experience. Blood 2010;115:4651-56.

* First FDA-approved competitor of Cerezyme ${ }^{\circledR}$.

30. www.news-medical.net/news/20100712/FDA-accepts-Protalixs-taliglucerasealfa-NDA-assigns-PDUFA-action-date.aspx (last accessed $11^{\text {th }}$ Feb 2011).

31. Biomarin pipeline: GALNS for MPS IVA (Morquio A disease). www.bmrn.com/pipeline/morquio-syndrome.php (last accessed $11^{\text {th }}$ Feb 2011)

32. Shire pipeline: $\underline{w w w . s h i r e . c o m / s h i r e p l c / e n / r d / p i p e l i n e ~(l a s t ~ a c c e s s e d ~} 11^{\text {th }} \mathrm{Feb}$ 2011)

33. Platt FM, Jeyakumar M. Substrate reduction therapy. Acta Paediatr Suppl 2008;97: 88-93

34. Shukla GS, Shukla A, Radin NS. Gangliosides inhibit glucosylceramide synthase: a possible role in ganglioside therapy. J Neurochem 1991;56:2125-32

* First evidence of the potential use of iminosugars for SRT. 
35. Platt FM, Jeyakumar M, Andersson U, et al. Inhibition of substrate synthesis as a strategy for glycolipid lysosomal storage disease therapy. J Inherit Metab Dis $2001 ; 24: 275-90$

36. Radin NS. Treatment of Gaucher disease with an enzyme inhibitor. Glycoconjugate J 1996;13:153-7

37. Schiffmann R, Fitzgibbon EJ, Harris C, et al. Randomized, controlled trial of miglustat in Gaucher's disease type 3. Ann Neurol 2008;64:514-22

38. Cox T, Lachman, R, Hollak C, et al. Novel oral treatment of Gaucher's disease with $N$-butyldeoxynojirimycin (OGT 918) to decrease substrate biosynthesis. Lancet 2000;355:1481-5

39. Platt FM, Butters TD. Substrate reduction therapy. In JA, Cabrera-Salazar MA, eds. Lysosomal storage disorders. NY: Springer, 2007:153-68

40. Cabrera-Salazar MA, Novelli E, Barranger JA. Gene therapy for the lysosomal storage disorders. Curr Opin Mol Ther 2002;4:349-58

41. Sands MS. Gene therapy. In Platt FM, Walkley SU, eds. Lysosomal Disorders of the Brain. Oxford: Oxford University Press, 2004:409-30

42. Snyder EY, Daley GQ, Goodell M. Taking stock and planning for the next decade: realistic prospects for stem cell therapies for the nervous system. $\mathrm{J}$ Neurosci Res 2004;76:157-68

43. Lee JP, Clark D, Jeyakumar M, et al. Neural stem cell therapy in lysosomal storage disorders. In Barrange JA, Cabrera-Salazar MA, eds. Lysosomal storage disorders. NY: Springer, 2007:197-216

44. Ringden O, Groth CG, Erikson A, et al. Ten years' experience of bone marrow transplantation for Gaucher disease. Transplantation 1995;59:864-70 
45. Pollack A. FDA halts 27 gene therapy trials after illness: leukemia-like cases in 2 children in France prompt the action. NY Times (print) 2003: A1, A17

46. Marshall E. Gene therapy. Second child in French trial is found to have leukemia. Science 2003;299:320

47. Bonetta L. Leukemia case triggers tighter gene-therapy controls. Nat Med $2002 ; 8: 1189$

48. Fan JQ, Ishii S, Asano N, Suzuki Y. Accelerated transport and maturation of lysosomal $\alpha$-galactosidase A in Fabry lymphoblasts by an enzyme inhibitor. Nat Med 1999;5:112-5

\section{** Proof of principle of the PC concept for the treatment of LSDs.}

49. Fan JQ. A counterintuitive approach to treat enzyme deficiencies: use of enzyme inhibitors for restoring mutant enzyme activity. Biol Chem 2007;389:1-11

50. Suzuki Y, Ichinomiya S, Kurosawa M, et al. Chemical chaperone therapy: clinical effect in murine GM1-gangliosidosis. Ann Neurol 2007;62: 671-5

51. Fan JQ, Ishii S. Active-site-specific chaperone therapy for Fabry disease. Yin and Yang of enzyme inhibitors. FEBS J 2007;274:4962-71.

52. Porto C, Cardone M, Fontana F, et al. The Pharmacological chaperone $\mathrm{N}$ butyldeoxynojirimycin enhances enzyme replacement therapy in Pompe disease fibroblasts. Mol Ther 2009;17:964-71

\section{* An illustrative example of the potential of combined therapies towards LSDs (ERT-PCT).}

53. Yu Z, Sawkar AR, Kelly JW. Pharmacologic chaperoning as a strategy to treat Gaucher disease. FEBS J 2007;274:4944-5017 
54. Treiber A, Morand O, Clozel M. The pharmacokinetics and tissue distribution of the glucosylceramide synthase inhibitor miglustat in the rat. Xenobiotica $2007 ; 37: 298-314$

55. Benjamin ER, Flanagan JJ, Schilling A, et al. The pharmacological chaperone 1deoxygalactonojirimycin increases $\alpha$-galactosidase A levels in Fabry patient cell lines. J Inherit Metab Dis 2009;32:424-40

56. Wang X, Koulov AV, Kellner WA, et al. Chemical and biological folding contribute to temperature-sensitive DeltaF508 CFTR trafficking. Traffic $2008 ; 9: 1878-93$

57. Becq F, Cystic fibrosis transmembrane conductance regulator modulators for personalized drug treatment of cystic fibrosis. Drugs 2010;70:241-59.

58. Sánchez-Ollé G, Duque J, Egido-Gabás M, et al. Promising results of the chaperone effect caused by iminosugars and aminocyclitol derivatives on mutant glucocerebrosidases causing Gaucher disease. Blood Cell Mol Dis 2009;42:15966

59. Fan JQ. A contradictory treatment for lysosomal storage disorders: inhibitors enhance mutant enzyme activity. Trends Pharmacol Sci 2003;24:355-60 * This paper summarizes the basic requirements to design PCs.

60. Stuzt AE. Iminosugars as glycosidase inhibitors. Weinheim: Wiley-VCH, 1999.

61. Compain P, Martin OR. Iminosugars: From synthesis to therapeutic applications. Weinheim: Wiley-VCH, 2008.

62. Butters TD. Gaucher disease. Curr Opin Chem Biol 2007;11:412-8

63. Sawkar AR, Adamski-Werner SL, Cheng WC, et al. Gaucher disease-associated glucocerebrosidases show mutation-dependent chemical chaperoning profiles. Chem Biol 2005; 12:1235-44 
64. Sawkar AR, Cheng WC, Beutler E, et al. Chemical chaperones increase the cellular activity of N370S $\beta$-glucosidase: a therapeutic strategy for Gaucher disease. Proc Natl Acad Sci USA 2002; 99:15428-33

65. Alfonso P, Pampín S, Estrada J, et al. Miglustat (NB-DNJ) works as a chaperone for mutated acid $\beta$-glucosidase in cells transfected with several Gaucher disease mutations. Blood Cell Mol Dis 2005;35:268-76

66. Yu ZQ, Sawkar AR, Whalen LJ, et al. Isofagomine- and 2,5-anhydro-2,5-iminoD-glucitol-based glucocerebrosidase pharmacological chaperones for Gaucher disease intervention. J Med Chem 2007;50:94-100

67. Chang HH, Asano N, Ishii S, et al. Hydrophilic iminosugar active-site-specific chaperones increase residual glucocerebrosidase activity in fibroblasts from Gaucher patients. FEBS J 2006;273:4082-92

\section{* First evidences of the chaperoning properties of hydrophilic iminosugars such as IFG.}

68. Steet RA, Chung S, Wustman B, et al. The iminosugar isofagomine increases the activity of N370S mutant acid $\beta$-glucosidase in Gaucher fibroblasts by several mechanisms. Proc Natl Acad Sci USA 2006;103:13813-8

69. Steet R, Chung S, Lee W-S, et al. Selective actions of the iminosugar isofagomine, a pharmacological chaperone for mutant forms of acid- $\beta$ glucosidase. Biochem Pharmacol 2007;73:1376-83

70. Khanna R, Benjamin ER, Pellegrino L, et al. The pharmacological chaperone isofagomine increases the activity of the Gaucher disease L444P mutant form of $\beta$-glucosidase. FEBS J 2010;277:1618-38.

71. Safety study of AT2101 in adult patients with type 1 Gaucher disease currently receiving enzyme replacement therapy. NCT00433147 
72. A study to evaluate and characterize the effect of pharmacological chemicals on blood from patients with Gaucher disease. NCT00465062

73. A long-term extension study of AT2101 in type 1 Gaucher patients. NCT00813865

74. A study of oral AT2101 in treatment-naïve patients with Gaucher disease. NCT00446550

75. Amicus Therapeutics. Available from:

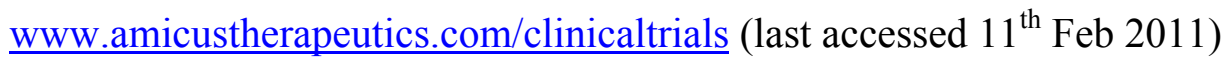

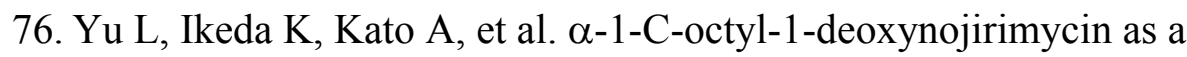
pharmacological chaperone for Gaucher disease. Bioorg Med Chem $2006 ; 14: 7736-44$

77. Compain P, Martin OR, Boucheron C, et al. Design and synthesis of highly potent and selective pharmacological chaperones for the treatment of Gaucher's disease. ChemBioChem 2006;7;1356-9

78. Whereas in classical iminosugars the endocyclic nitrogen locates lone electron pair in an $\mathrm{sp}^{3}$ orbital, in compounds incorporating nitrogen atom with substantial $\mathrm{sp}^{2}$ character the lone pair locates in an axial $\mathrm{p}$ orbital. This situation reinforces the electronic contribution to the anomeric effect and fixes the configuration at the anomeric carbon.

79. Díaz-Pérez VM, García-Moreno MI, Ortiz Mellet C, et al. Generalized anomeric effect in action: Synthesis and evaluation of stable reducing indolizidine glycomimetics as glycosidase inhibitors. J. Org. Chem. 2000;65:136-43

80. García-Moreno MI, Díaz-Pérez P, Ortiz Mellet C, García Fernández JM. Castanospermine-trehazolin hybrids: a new family of glycomimetics with tuneable glycosidase inhibitory properties. Chem Commun 2002:848-9 
81. García-Moreno MI, Díaz-Pérez P, Ortiz Mellet C, García Fernández JM. Synthesis and evaluation of isourea-type glycomimetics related to the indolizidine and trehazolin glycosidase inhibitor families. J Org Chem $2003 ; 68: 8890-901$

82. Díaz-Pérez P, García-Moreno MI, Ortiz Mellet C, García Fernández JM. Synthesis and comparative glycosidase inhibitory properties of reducing castanospermine analogues. Eur J Org Chem 2005:2903-13

83. Aguilar M, Díaz-Pérez P, García-Moreno MI, et al. Synthesis and biological evaluation of guanidine-type iminosugars. J Org Chem 2008;73:1995-8

84. Sánchez-Fernández E, Rísquez-Cuadro R, Aguilar-Moncayo M, et al. Generalized anomeric effect in gem-diamines: Stereoselective synthesis of $\alpha-N$ linked disaccharide mimics. Org Lett 2009;11:3306-9

85. Luan Z, Higaki K, Aguilar-Moncayo M, et al. Chaperone activity of bicyclic nojirimycin analogues for Gaucher mutations in comparison with $N$-(n-nonyl)deoxynojirimycin. ChemBioChem 2009;10:2780-92

86. Ogawa S, Ashiura M, Uchida C, et al. Synthesis of potent $\beta$-Dglucocerebrosidase inhibitors: $N$-alkyl- $\beta$-valienamines. Bioorg Med Chem Lett $1996 ; 6: 929-32$

87. Lin H, Sugimoto Y, Ohsaki Y, et al. $N$-Octyl- $\beta$-valienamine up-regulates activity of F213I mutant $\beta$-glucosidase in cultured cells: a potential chemical chaperone therapy for Gaucher disease. Biochim Biophys Acta 2004;1689:21928

88. Luan Z, Li L, Ninomiya H, et al. The pharmacological chaperone effect of $N$ octyl- $\beta$-valienamine on human mutant acid $\beta$-glucosidases. Blood Cell Mol Dis 2010;44:48-54 
89. Matsuda J, Suzuki O, Oshima A, et al. Chemical chaperone therapy for brain pathology in G(M1)-gangliosidosis. Proc Natl Acad Sci USA 2003;100:15912-7

90. Egido-Gabás M, Canals D, Casas J, et al. Aminocyclitols as pharmacological chaperones for glucocerebrosidase, a defective enzyme in Gaucher disease. ChemMedChem 2007;2:992-4

91. Maegawa GH, Tropak MB, Buttner JD, et al. Identification and characterization of ambroxol as an enzyme enhancement agent for Gaucher disease. J Biol Chem $2009 ; 284: 23502-16$

\section{* PCs (ABX) discovered by library high throughput screening.}

92. Maegawa GH, Tropak M, Buttner J, et al. Pyrimethamine as a potential pharmacological chaperone for late-onset forms of $\mathrm{G}_{\mathrm{M} 2}$ gangliosidosis. J Biol Chem. 2007;282:9150-61

93. A phase I study of pyrimethamine in patients with $\mathrm{G}_{\mathrm{M} 2}$ gangliosidosis. NCT00679744

94. Bultron G, Kacena K, Pearson D, et al. The risk of Parkinson's disease in type 1 Gaucher disease. J Inherit Metab Dis 2010;33:167-73

95. Velayati A, Yu WH, Sidransky E. The role of glucocerebrosidase mutations in Parkinson disease and Lewy body disorders. Curr. Neurol. Neurosci Rep $2010 ; 10: 190-8$

96. Sidransky E, Nalls MA, Aasly JO, et al. Multicenter analysis of glucocerebrosidase mutations in Parkinson's disease. New Engl J Med 2009;361:1651-61

97. Morello JP, Salahpour A, Laperriere A, et al Pharmacological chaperones rescue cell-surface expression and function of misfolded V2 vasopressin receptor mutants. J Clin Invest 2000;105:887-95 
98. Amaral MD. Therapy through chaperones: Sense or antisense? Cystic fibrosis as a model disease. J Inherit Metab Dis 2006;29:477-87

99. Barral JM, Broadley SA, Schaffar G, Hartl FU (2004) Roles of molecular chaperones in protein misfolding diseases. Semin Cell Dev Biol 15: 17-29

100. Jones GW, Tuite MF (2005) Chaperoning prions: the cellular machinery for propagating an infectious protein? Bioessays 27: 823-832

101. Muchowski PJ,Wacker JL (2005) Modulation of neurodegeneration by molecular chaperones. Nat Rev Neurosci 6: 11-22

102. Luan Z, Higaki K, Aguilar-Moncayo M, Li L, Ninomiya H, Nanba E, Ohno K, García-Moreno MI, Ortiz Mellet C, García Fernández JM, Suzuki Y. A fluorescent $\mathrm{sp}^{2}$-iminosugar with pharmacological chaperone activity for Gaucher disease: synthesis and intracellular distribution studies. ChemBioChem $2010 ; 11: 2353-64$

103. Wang GN, Reinkensmeier G, Zhang SW, et al. Rational design and synthesis of highly potent pharmacological chaperones for treatment of N370S mutant Gaucher disease. J Med Chem 2009;52: 3146-9

104. Witte MD, Kallemeijn WW, Aten J, et al. Ultrasensitive in situ visualization of active glucocerebrosidase molecules. Nat Chem Biol 2010;6:907-13

105. Kornhaber GJ, Tropak MB, Maegawa GH, et al. Isofagomine induced stabilization of glucocerebrosidase. ChemBioChem 2008;9: 2643-9

106. Tropak MB, Kornhaber GJ, Rigat BA, et al. Identification of pharmacological chaperones for Gaucher disease and characterization of their effects on $\beta$ glucocerebrosidase by hydrogen/deuterium exchange mass spectrometry. ChemBioChem 2008;9:2650-62 
107. Shen JS, Edwards NJ, Hong YB, Murray GJ. Isofagomine increases lysosomal delivery of exogenous glucocerebrosidase. Biochem Biophys Res Commun 2008;369:1071-5

108. Flanagan JJ, Rossi B, Tang K, et al. The pharmacological chaperone 1deoxynojirimycin increases the activity and lysosomal trafficking of multiple mutant forms of acid $\alpha$-glucosidase. Human Mutation 2009;30:1683-92

109. Marie I. Combined therapy of imiglucerase and miglustat in Gaucher disease with severe bone complications. Press Medicale 2009;38:2S68-2S70

110. Johnston JA, Ward CL, Kopito RR. Aggresomes: A cellular response to misfolded proteins. J Cell Biol 1998;143:1883-98

111. Mu T-W, Ong DST, Wang Y-J, et al. Chemical and biological approaches synergize to ameliorate protein-folding diseases. Cell 2008: 134, 769-81

201. Kelly JW, Sawkar AR, Beutler E, et al. Chemical chaperones and their effect upon the cellular activity of $\beta$-glucosidase. WO2004/037373

202. Fan J-Q, Ishii S, Asano N. Method for increasing the activity of lysosomal enzymes. US2003/0119874

203. Fan J-Q, Ishii S, Asano N. Method for increasing the activity of lysosomal enzymes. US2005/0113415

204. Fan J-Q, Ishii S, Asano N. Method for increasing the activity of lysosomal enzymes. US2007/0021381

205. Mugrage B, Tretyakov A. New methods for preparing isofagomine and its derivatives. US2008/064559

206. Mugrage B, Tretyakov A, Fuerst D, et al. New methods for preparing isofagomine and its derivatives. WO2008/144773 
207. Mugrage B, Sheth KA, Palling D, Rybcynski PJ. Tartrate salt of isofagomine and methods of use. WO2007/140212

208. Mugrage B, Sheth KA, Palling D, Rybcynski PJ. Tartrate salt of isofagomine and methods of use. US2009/0176830

209. Wustman B. Treatment of CNS disorders associated with mutations in genes encoding lysosomal enzymes. WO2006/133446

210. Lockhart D. Treatment of Gaucher disease with specific pharmacological chaperones and monitoring treatment using surrogate markers. WO2008/128106

211. Lockhart D, Wustman B. Dosing regimens for the treatment of lysosomal storage diseases using pharmacological chaperones. WO2008/134628

212. Fan J-Q, Zhu X, Sheth K. Hydroxy piperidine derivatives to treat Gaucher disease. WO2005/046612

213. Fan J-Q, Zhu X, Sheth K. Hydroxy piperidine derivatives to treat Gaucher disease. US2010/0189708

214. Boyd R, Lee G. Methods for preventing and/or treating degenerative disorders of the central nervous system. WO2010/118282

215. Boyd R, Lee G. Methods for preventing and/or treating lysosomal storage disorders. WO2010/118283

216. Martin OR, Compain P, Boucheron C, Asano N. Novel compounds of the family of iminosugars, uses thereof for treating lysosomal diseases, and methods for preparing same. WO2006/136714

217. Fan JQ, Zhu X, Sheth K. Glucoimidazole and polyhydroxycyclohexenyl amine derivatives to treat Gaucher disease. US2005/0137223

218. Fan JQ, Zhu X, Sheth K. Glucoimidazole and polyhydroxycyclohexenyl amine derivatives to treat Gaucher disease. WO2005/046611 
219. García Fernández JM, Ortiz Mellet C, Garcia Moreno MI, et al. Compounds promoting the activity of mutant glycosidases. WO2010/046517

220. Llebaria Soldevilla A, Casas Brugulat J, Egido Gabás M, et al. Ciclohexano hexasubstituido activador de la enzima $\beta$-glucosidass, procedimiento de síntesis, composición farmacéutica que lo contiene y sus aplicaciones. EP 2289853

221. Mahuran DJ, Tropak MB, Buttner JD, et al. Method for treating Gaucher disease. WO2009/038695

222. Mahuran D, Tropak M, Withers S. Treatment of Tay Sachs or Sandhoff disease by enhancing hexosaminidase activity. WO2004/103368

223. Mahuran DJ, Tropak MB, Buttner JD, et al. Compositions and methods for enhancing enzyme activity in Gaucher GM1-gangliosidosis/Morquio B disease and Parkinson's disease.WO2009/049421

224. Mahuran DJ, Tropak MB, Buttner JD, et al. Compositions and methods for enhancing enzyme activity in Gaucher GM1-gangliosidosis/Morquio B disease and parkinson's disease.WO2009/049422

225. Futerman A, Sussman JL, Silman I, et al. Gaucher disease drugs and methods to identifying same. US2007/0166813

226. Kawamura A, Roach AG, Wilson FX, et al. Treatment of protein folding disorders. WO2009/066069

227. Wilson FX, Nash RJ, Horne G, et al. Treatment of lysosomal storage disorders and other proteostatic diseases. WO2010/015816

228. Wilson FX, Storer R, Kawamura A, et al. Drug combination for the treatment of proteostatic diseases. WO2010/116141 
Article highlights box.

- Active-site specific binders have the potential to assist mutant proteins to fold properly, acting as PCs that rescue the enzyme from cellular recycling system and restore its catalytic activity.

- PCs have arisen as an alternative to overcome the limitations of ERT, currently the cornerstone in the treatment for lysosomal enzymopathies.

- GD, the most prevalent lysosomal storage disorder and probably the best studied, is usually considered a valid model for other lysosomal enzymopathies. Lessons learned from GD research are valuable tools for approaching less common LSDs.

- As a consequence of a profitable academy-industry synergy, the number of potential PCs is growing fast (several candidates already entered clinical phases).

- Future studies will not exclusively focus on new molecule design for restoring enzyme activity but also on investigating combining PCs with other therapeutic approaches (e. g. ERT).

PCs, pharmacologic chaperones; GD, Gaucher disease; LSD, lysosomal storage disorder, ERT, enzyme replacement therapy. 
Table 1. List of some LSD's with indication of the defective lysosomal enzyme and approximate worldwide prevalence.

\begin{tabular}{|c|c|c|}
\hline LSD & defective enzyme & cases per $10^{6}$ newborn ${ }^{\mathrm{a}}$ \\
\hline Pompe disease & acid $\alpha$-glucosidase & 25 \\
\hline Gaucher disease & $\beta$-glucocerebrosidase & 50 \\
\hline Fabry disease & $\alpha$-galactosidase $\mathrm{A}$ & 12.5 \\
\hline $\mathrm{G}_{\mathrm{M} 1}$ gangliosidosis & acid $\beta$-galactosidase & 10 \\
\hline Tay-Sachs disease & $\beta$-hexosaminidase $\mathrm{A}$ & 3 \\
\hline Sandhoff disease & $\beta$-hexosaminidase $\mathrm{B}$ & 3 \\
\hline Niemann-Pick disease & acid sphigomyelinase & 10 \\
\hline Krabbe disease & galactocerebrosidase & 10 \\
\hline Farber disease & acid ceramidase & $<1$ \\
\hline metacromatic leukodystrophy & arylsulfatase A & 6 \\
\hline Hurler-Scheie disease & $\alpha$-iduronidase & 10 \\
\hline Hunter disease & iduronate-2-sulfatase & 10 \\
\hline Sanfilippo disease A & heparan-2-sulfatase & 14 \\
\hline Sanfilippo disease B & $\alpha-N$-acetylglucosaminidase & \\
\hline Sanfilippo disease $\mathrm{C}$ & $\begin{array}{l}\text { acetyl-CoA: } \alpha \text {-glucosamine } \\
N \text {-acetyltransferase }\end{array}$ & \\
\hline Sanfilippo disease D & $\begin{array}{l}\mathrm{N} \text {-acetylglucosamine-6- } \\
\text { sulfate sulfatase }\end{array}$ & \\
\hline Morquio disease $\mathrm{A}$ & acid $\beta$-galactosidase & 5 \\
\hline Morquio disease $\mathrm{B}$ & arylsulfatase B & \\
\hline Sly disease & $\beta$-glucuronosidase & 4 \\
\hline
\end{tabular}




\begin{tabular}{|l|l|l|}
\hline$\alpha$-mannosidosis & acid $\alpha$-mannosidase & 1 \\
\hline$\beta$-mannosidosis & acid $\beta$-mannosidase & 1 \\
\hline fucosidosis & acid $\alpha$-fucosidase & 5 \\
\hline sialidosis & sialidase & $<1$ \\
\hline
\end{tabular}

${ }^{\mathrm{a}}$ Data retrieved from www.orpha.net (last accessed $11^{\text {th }}$ Feb 2011) 
Table 2. Clinical features of Gaucher's disease variants.

\begin{tabular}{|c|c|c|c|}
\hline & \multicolumn{3}{|l|}{ Gaucher's disease } \\
\hline & Type I & Type 2 & Type III \\
\hline onset age & $\begin{array}{l}\text { childhood to } \\
\text { adulthood }\end{array}$ & newborn & $\begin{array}{l}\text { childhood to } \\
\text { adolescence }\end{array}$ \\
\hline $\begin{array}{l}\text { haematological } \\
\text { affection }\end{array}$ & + to +++ & +++ & + to +++ \\
\hline visceromegalia & $\begin{array}{l}+ \text { to }+++ \\
\text { progressive }\end{array}$ & +++ & $\begin{array}{l}+ \text { to }+++ \\
\text { progressive }\end{array}$ \\
\hline skeletal affection $^{\mathrm{a}}$ & + to +++ & nd & + to +++ \\
\hline neuronal affection & - & +++ & + to +++ \\
\hline live span & $\begin{array}{l}\text { shortened life if } \\
\text { untreated } \\
\text { poor life quality }\end{array}$ & $>2$ years & $\begin{array}{l}\text { childhood to early } \\
\text { adulthood }\end{array}$ \\
\hline incidence & $\begin{array}{l}1 \text { in } 20000-40000 \\
\text { live births }\end{array}$ & $\begin{array}{l}1 \text { in }>100000 \text { live } \\
\text { births }\end{array}$ & $\begin{array}{l}1 \text { in } 50000-100000 \\
\text { live births }\end{array}$ \\
\hline & pan-ethnic $^{b}$ & pan-ethnic & pan-ethnic $^{\mathrm{c}}$ \\
\hline+++ & degrees of sever & & \\
\hline
\end{tabular}

${ }^{a}$ Over $95 \%$ of patients feature radiologic abnormalities. ${ }^{b}$ Particularly high incidence among Askenazi Jew population, peaking up at 1 in 450 live births. ${ }^{c}$ Higher incidence among Swedish population. 
Table 3. Common mutations in Gaucher disease variants.

\begin{tabular}{|l|l|l|l|}
\hline $\begin{array}{l}\text { gene mutation } \\
(\mathrm{cDNA})\end{array}$ & allele & relative frequency & GD type \\
overall $(\mathrm{AJ})^{\mathrm{a}}(\%)$ & association \\
\hline c. $1226 \mathrm{~A}>\mathrm{G}$ & $\mathrm{N} 370 \mathrm{~S}$ & $29(77)$ & type I \\
\hline c. $1448 \mathrm{~T}>\mathrm{C}$ & L444P & $38(3.3)$ & type 2 (mostly) \\
\hline c. $84 \mathrm{dupG}$ & $84 \mathrm{gg}$ & $<1(2.5)$ & n. d. \\
\hline c. $115+1 \mathrm{G}>\mathrm{A}$ & IVS2+1G $>$ A & $<1(12)$ & n. d. \\
\hline
\end{tabular}

${ }^{\mathrm{a}}$ AJ stands for Askenazy Jews. ${ }^{\mathrm{b}}$ n. d. stands for not sufficiently documented. 
Table 4. Summary of advantages and limitations of the most promising therapeutic approaches for GD.

\begin{tabular}{|c|c|c|c|}
\hline Therapy & Advantages & Limitations & $\begin{array}{l}\text { Approved } \\
\text { treatments }\end{array}$ \\
\hline \multirow[t]{3}{*}{ ERT } & $\begin{array}{l}\text { efficiency rate for Type } 1 \\
\text { patients }(>85 \%)\end{array}$ & $\begin{array}{l}\text { poor enzyme } \\
\text { biodistribution }\end{array}$ & $\begin{array}{l}\text { Cerezyme }{ }^{\circledR}, \\
\text { Genzyme }\end{array}$ \\
\hline & $\begin{array}{l}\text { greatly improved quality } \\
\text { of life }\end{array}$ & $\begin{array}{l}\text { type } 2 \text { and } 3 \text { patients are } \\
\text { refractory to ERT }\end{array}$ & $\begin{array}{l}\text { Veraglucerase, } \\
\text { Shire }\end{array}$ \\
\hline & long term experience & costs & $\begin{array}{l}\text { Taliglucerase, } \\
\text { Protalix-Pfizer }\end{array}$ \\
\hline SRT & oral administration & $\begin{array}{l}\text { poor improvement-to-dose } \\
\text { ratio }\end{array}$ & Miglustat, Actelion \\
\hline \multirow[t]{2}{*}{ PCT } & enhanced biodistribution & limited clinical experience & \multirow[t]{2}{*}{ investigational } \\
\hline & target the disease cause & $\begin{array}{l}\text { only amenable to } \\
\text { refolding "responsive" } \\
\text { mutations }\end{array}$ & \\
\hline \multirow{2}{*}{$\begin{array}{l}\text { GT and } \\
\text { STC }\end{array}$} & intend sustained correction & procedure-related risks & \multirow[t]{2}{*}{ investigational } \\
\hline & target the disease cause & limited clinical experience & \\
\hline
\end{tabular}


Table 5. Patenting activity concerning PCT in GD.

\begin{tabular}{|c|c|c|}
\hline Patent no. ${ }^{a}$ & Applicant & Reference \\
\hline WO2004/037373 & Scripps Research Institute, San Diego, US & 201 \\
\hline US2003/0119874 & \multirow[t]{3}{*}{ Mount Sinai School of Medicine, New York, US } & 202 \\
\hline US2005/0113415 & & 203 \\
\hline US2007/0021381 & & 204 \\
\hline US2008/064559 & \multirow[t]{2}{*}{ Amicus Therapeutics, New Jersey, US } & 205 \\
\hline WO2008/144773 & & 206 \\
\hline WO2007/140212 & \multirow[t]{2}{*}{ Amicus Therapeutics, New Jersey, US } & 207 \\
\hline US2009/0176860 & & 208 \\
\hline WO2006/133446 & \multirow[t]{3}{*}{ Amicus Therapeutics, New Jersey, US } & 209 \\
\hline WO2008/128106 & & 210 \\
\hline WO2008/134628 & & 211 \\
\hline WO2005/046612 & \multirow[t]{2}{*}{ Amicus Therapeutics, New Jersey, US } & 212 \\
\hline US2010/0189708 & & 213 \\
\hline $\begin{array}{l}\text { WO2010/118282 } \\
\text { WO2010/118283 }\end{array}$ & Amicus Therapeutics, New Jersey, US & $\begin{array}{l}214 \\
215\end{array}$ \\
\hline WO2006/136714 & CNRS \& Univ. Orleans, France & 216 \\
\hline WO2005/046611 & \multirow[t]{2}{*}{ Amicus Therapeutics, New Jersey, US } & 217 \\
\hline US2005/0137223 & & 218 \\
\hline WO2010/046517 & $\begin{array}{l}\text { CSIC \& Univ. Sevilla, Spain } \\
\text { International Univ. Health \& Welfare \& Univ. Tottori, } \\
\text { Japan }\end{array}$ & 219 \\
\hline EP 2289853 & CSIC, Barcelona, Spain & 220 \\
\hline
\end{tabular}




\begin{tabular}{|l|l|l|}
\hline WO2009/038695 & Exar Corporation, US \& The Hospital for Sick & 221 \\
& Children, Toronto, Canada & \\
\hline WO2009/049421 & The Hospital for Sick Children, Toronto, Canada & 223 \\
\hline US2007/0166813 & Weizmann Institute of Science, Rehovot, Israel & 224 \\
\hline WO2009/066069 & Summit Corporation, Oxford, UK & 225 \\
\hline WO2010/015816 & & 227 \\
\hline WO2010/116141 & Summit Corporation, Oxford, UK & 228 \\
\hline
\end{tabular}

${ }^{\mathrm{a}}$ Collected from free patent data bases (Espacenet and Wipo) until Nov 2010. 


\section{Figure, Scheme and Chart Legends}

Figure 1. Wild-type (A) vs. mutant protein trafficking pathways (B).

Figure 2. Catabolic pathways of sphingolipids highlighting the enzymes involved in the most common LSDs.

Figure 3. Chronogram of therapeutic approaches towards Gaucher disease. ERT, SRT and PCT stand for Enzyme Replacemet Therapy, Substrate Reduction Therapy and

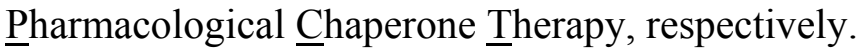

Figure 4. Schematic $\beta$-glucocerebrosidase metabolism in healthy (A) and GD cells (B) and the intended effect in lysosomal performance of the distinct therapeutic approaches: ERT (C), SRT (D) and PCT (E) (adapted from reference [5]).

Chart 1. Iminosugars under investigation as pharmacological chaperones for GD.

Chart 2. Isofagomine derivatives under investigation as pharmacological chaperones for GD.

Chart 3. Non-conventional iminosugar derivatives under investigation as pharmacological chaperones for GD.

Chart 4. $\beta$-Glucocerebrosidase aminocyclitol-type glycomimetics under investigation as pharmacological chaperones for GD.

Chart 5. Non-glycomimetic pharmacological chaperones for GD discovered by HTS. 